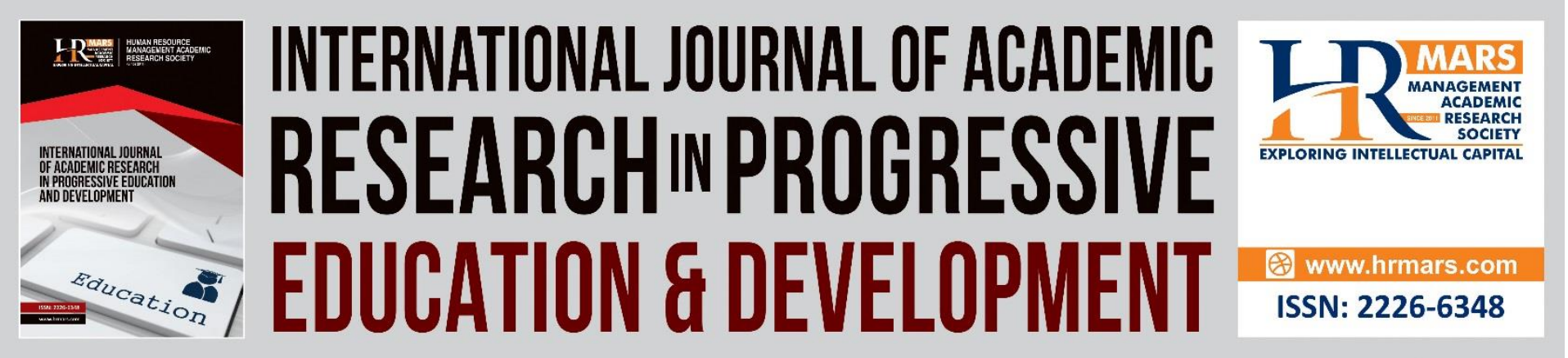

\title{
Game-Based Learning Application for Children with Autism Spectrum Disorder using Participatory Design
}

\section{Sara Reisi Dehkordi, Marina Ismail, Norizan Mat Diah}

To Link this Article: http://dx.doi.org/10.6007/IJARPED/v11-i1/11931

DOI:10.6007/IJARPED/v11-i1/11931

Received: 06 November 2021, Revised: 08 December 2021, Accepted: 25 December 2021

Published Online: 01 January 2022

In-Text Citation: (Dehkordi et al., 2022)

To Cite this Article: Dehkordi, S. R., Ismail, M., \& Diah, N. M. (2022). Game-Based Learning Application for Children with Autism Spectrum Disorder using Participatory Design. International Journal of Academic Research in Progressive Education and Development, 11(1), 1-13.

Copyright: (c) 2022 The Author(s)

Published by Human Resource Management Academic Research Society (www.hrmars.com)

This article is published under the Creative Commons Attribution (CC BY 4.0) license. Anyone may reproduce, distribute, translate and create derivative works of this article (for both commercial and non-commercial purposes), subject to full attribution to the original publication and authors. The full terms of this license may be seen at: http://creativecommons.org/licences/by/4.0/legalcode

Vol. 11(1) 2021, Pg. 1 - 13

Full Terms \& Conditions of access and use can be found at http://hrmars.com/index.php/pages/detail/publication-ethics 


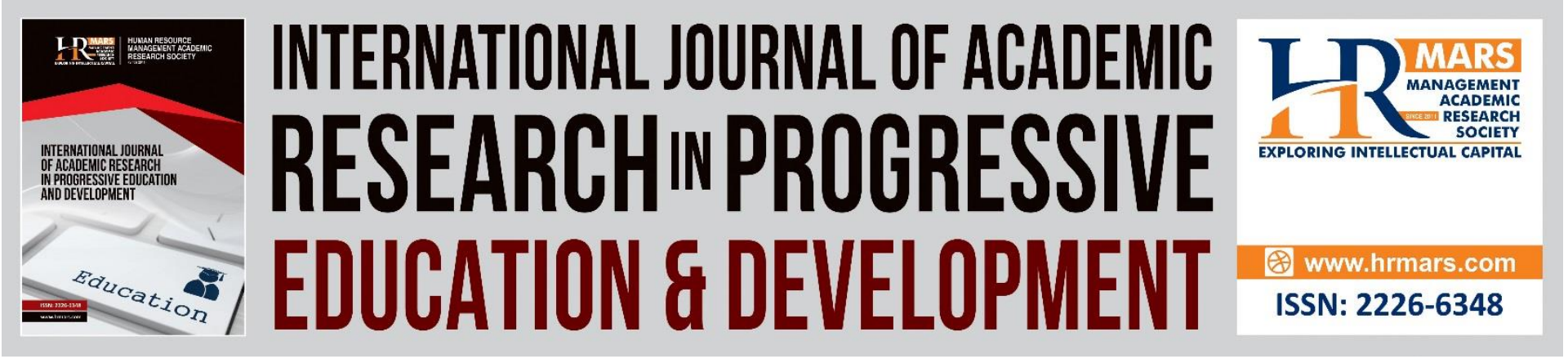

\title{
Game-Based Learning Application for Children with Autism Spectrum Disorder using Participatory Design
}

\author{
Sara Reisi Dehkordi, Marina Ismail, Norizan Mat Diah \\ Faculty of Computer and Mathematical Sciences, Universiti Teknologi MARA, \\ 40450 Shah Alam, Selangor, Malaysia
}

Email: sarahraissy@yahoo.com, Marina@fskm.uitm.edu.my,norizan@fskm.uitm.edu.my

\begin{abstract}
This paper aimed to devise a means to design game-based learning and develop an application game for children with autism spectrum disorder (ASD) using the participatory design (PD) method. A total of 15 participants from Khaneye Mehre Autism School in Tehran, Iran, were involved in this study. The engagement participatory sessions supplied the necessary information to facilitate the design process and understand the children's preference between the different design stimuli in individuals as informants by allowing them to be part of design activities. In addition, some value practices and design methods informed by relevant PD projects in the healthcare and public sectors were discussed such as an effective role of designers require adequate communication skills from participants. Based on the findings, this study maintains that PD increases the chance that the result of a design process represents the values for future works.
\end{abstract}

Keywords: Autism, Autism Spectrum Disorder, Game-based Learning, Participatory Design

\section{Introduction}

Autism Spectrum Disorder (ASD) is a neurodevelopmental disorder with irregularities that adversely affect developmental process of children (Golestan, Soleiman \& Moradi, 2010). Because individuals with ASD have strong interests in video games, autism researchers have been increasingly interested in examining the effects of video game use (Mazurek, et al., 2015). Many researchers have focused on developing applications of game technology such as serious game (Khowaja, Salim, \& Al-Thani, 2019; Sik-Lanyi et al., 2019) learning game (Passerino \& Santarosa, 2008), video game (Hiniker, 2013) and etc. This study focused on designing a learning game on the iOS platform to improve multi-cue response and user engagement through the involvement of children in the design process. Furthermore, the participatory design (PD) method contributed to achieving the main goal.

The primary goal of traditional design methods is to observe and learn from children's behaviors and feedback while interacting with the final product. As a result, one of the design methods is to incorporate their contributions. According to (Druin, 2002), the method is focused on discovering children's thoughts and statements while acting in a variety of roles, 
including user, tester, informant, and design partner. The common methods for children to express their ideas are:

- User-centered design (Brunetti \& García, 2014; Howes et al., 2019; Roy, 2016; Miesenberger et al., 2020): focuses on the impact of technology on users, but traditionally, these users are involved only after the technology is designed.

- Learner-centered design (Good \& Robertson, 2006; Guzdial et al., 1995; King, 2006; Waraich \& Brna, 2008): provides the idea that all team members are learners.

- Contextual design (Aguirre et al., 2017): focuses on design strategies for users' engagement.

- PD (Benton \& Johnson, 2014; Drain \& Sanders, 2019; Malinverni et al., 2014): combines low-tech prototyping with the concept of peer co-designers.

- Informant design (Mazzone, 2008; Mazzone et al., 2008; Waraich \& Brna, 2008): involves experts and caregivers in the design process and considers potential children as users.

- Bonded design (Large et al., 2007; Large et al., 2006): combines various design types and groups children and adults into two intergenerational design teams.

- Cooperative inquiry (Chimbo, 2016; Druin, 2015): utilizes an intergenerational team of adults and children to maximize user involvement in design.

According to (Floyd et al., 1989), PD originated from a Scandinavian workplace and indicated that users are qualified enough to participate in the design process. There are five main learning outcomes associated with PD when working with children, which all members of the design team can learn: teamwork and collaboration, respect for design partners, content about the design topic, technology skills, and the design process itself (Druin, 2002). Additionally, working with children has resulted in the development of new approaches to collection development, cataloguing (metadata standards), and new technologies for information access and use (Druin, 2005).

Overall, in PD sessions, children and adults collaborate to develop low-tech prototypes. This strategy provides equal access to low-tech prototyping materials such as paper, markers, cardboard, boxes, and wires or drawing sketches on large pieces of paper for all participants. In addition, some advantages of PD, such as higher user satisfaction, clear understanding of users' needs and context of use, creating collaboration opportunities for user groups, potential to enhance life, and help to increase self-confidence for the users and ownership, were also highlighted in (Constantin et al., 2019).

Researchers typically employ the PD method in a variety of approaches, such as brainstorming (Gerling et al., 2015), comic book boarding (Hiniker, Sobel, \& Lee, 2017; Moraveji et al., 2007), exploratory design games (Brandt, 2006), interview (Drain \& Sanders, 2019), observation (Benton \& Johnson, 2014; Drain \& Sanders, 2019; Madsen et al., 2009), prototype review (Drain \& Sanders, 2019; Spinuzzi, 2004), questionnaire (Benton \& Johnson, 2014), and low tech prototype creation (Read, Sim, Gregory, Xu, \& Ode, 2013). When working with autistic children, sensitive considerations should be scrutinized regarding user involvement. The degree to which children contribute varies according to design type, ranging from low to high. Several studies reported success with the PD approach for children with autism using a variety of approaches. Focus groups (Boyle \& Arnedillo-Sánchez, 2016; Grond et al., 2019), brainstorming (Soysa et al., 2018), feedback on design choices (Frauenberger et al., 2012) (Kim et al., 2014), scenario creation (Millen, Cobb \& Patel, 2011), questionnaire (Boyle \& Arnedillo-Sánchez, 2016), narrative structure and personalized storage box (Malinverni et al., 
2014), observation (Madsen et al., 2009), and question and answer game (Porcino et al., 2014) are some of the methods used.

Unexpected situations can arise related to ethical considerations, such as attracting and retaining participants, supporting their engagement, extracting design information from PD activities, ending PD projects, and managing resources (Constantin et al., 2019). In other words, one of the core features of ASD impaired communication, significantly affects children's ability to participate in activities requiring face-to-face collaboration with others (Boyle \& Arnedillo-Sánchez, 2016). Moreover, the number of contributions taken into account when working with children or users with special needs can be drastically reduced due to difficulties in verbal articulation (Malinverni et al., 2016).

\section{Research Goal}

In this study, the methods to evaluate ideas such as questionnaires, interviews or brainstorming group talks were not appropriate for children with ASD due to the lack of communication skills, inflexible routines, stricter changes, and treatment plans. The reason is that they cannot accurately express their feelings. In addition, they are usually unaware of their needs and preferences to express them verbally during a participatory session. As a result, the characteristics of users must be facilitated by an adapted participatory session.

The goal of this paper is achieving the following objectives: (i) understand suitable design materials in a game-based technology with learning purpose and providing a list of refined engaging stimuli and game elements for users with ASD (ii) the participatory design model to elicit the children's contribution and establish a appropriate relation between users and therapists as caregivers during design process. A well-designed PD method encourage creative thinking and improve learning comprehension, challenges, fantasy, curiosity, and increases the motivations level to make the users stay in the contribution processes. Researchers and developers can use the result of this study as an initial guideline in guiding them for any employment in social attention learning content or learning content. The utilization in learning can enhance enjoyment feeling to the users. And can be used as engagement components by other researchers and developers

These PD sessions aimed to enable users to demonstrate their preferences for different design stimuli (social and non-social) through effective involvement and to adapt daily activities so that children felt safe and convenient, rather than bored, by providing a structured environment based on their routine classes. To achieve the aforementioned objectives, a short structure based on six sessions (Benton \& Johnson, 2014) was considered. Children diagnosed with ASD are motivated by different stimuli in various ways. As a result, it can be expected that incorporating their input into the design of these stimuli as rewards or game components presented to participants would increase the incentives' impact on participant motivation.

\section{Methodology}

The children generated a set of initial ideas and design proposals for this study. Following that, this study collected new requirements and perspectives from them. The PD, called the Bluebell technique by (Kelly et al., 2006), consists of three stages:

- Stage 1 (before play): Researcher(s) conducts the initial research and identifies the required activities, which are then validated by experts (therapists).

- Stage 2 (during play): Involvement of participants in design activities. 
- Stage 3 (after play): Involvement of researcher(s) in activity analysis.

Figure 1 depicts the PD stages and associated activities. The first phase involves the researcher conducting activities such as goal setting, initial research, and hypothesis creation to gain a better understanding of the whole project. Following that, the therapist validates materials and activities before initiating PD sessions, deciding whether to eliminate an activity or add more materials and strategies that are appropriate for users. Following that, six participatory design sessions are conducted, each with a distinct goal. Finally, the researcher then filters, classifies, and documents the filled-in data.

Children were determined as informants in this study because they are aware and informed about which design stimuli they prefer and dislike. Meanwhile, the teachers acted as facilitators, facilitating the participatory sessions tailored to the children's needs. While all participants received the same materials, teachers facilitated their use in the participatory activities as they see fit.

The final considerations after meeting with therapists could change during the participatory session. This was done to ensure an effective result by considering the users' mood and enthusiasm. The use of familiar and effective activities proposed in learning methods for participant design sessions in the definition of the activities and the creation of a feeling of continuity and progression between the different sessions was observed in this study. 


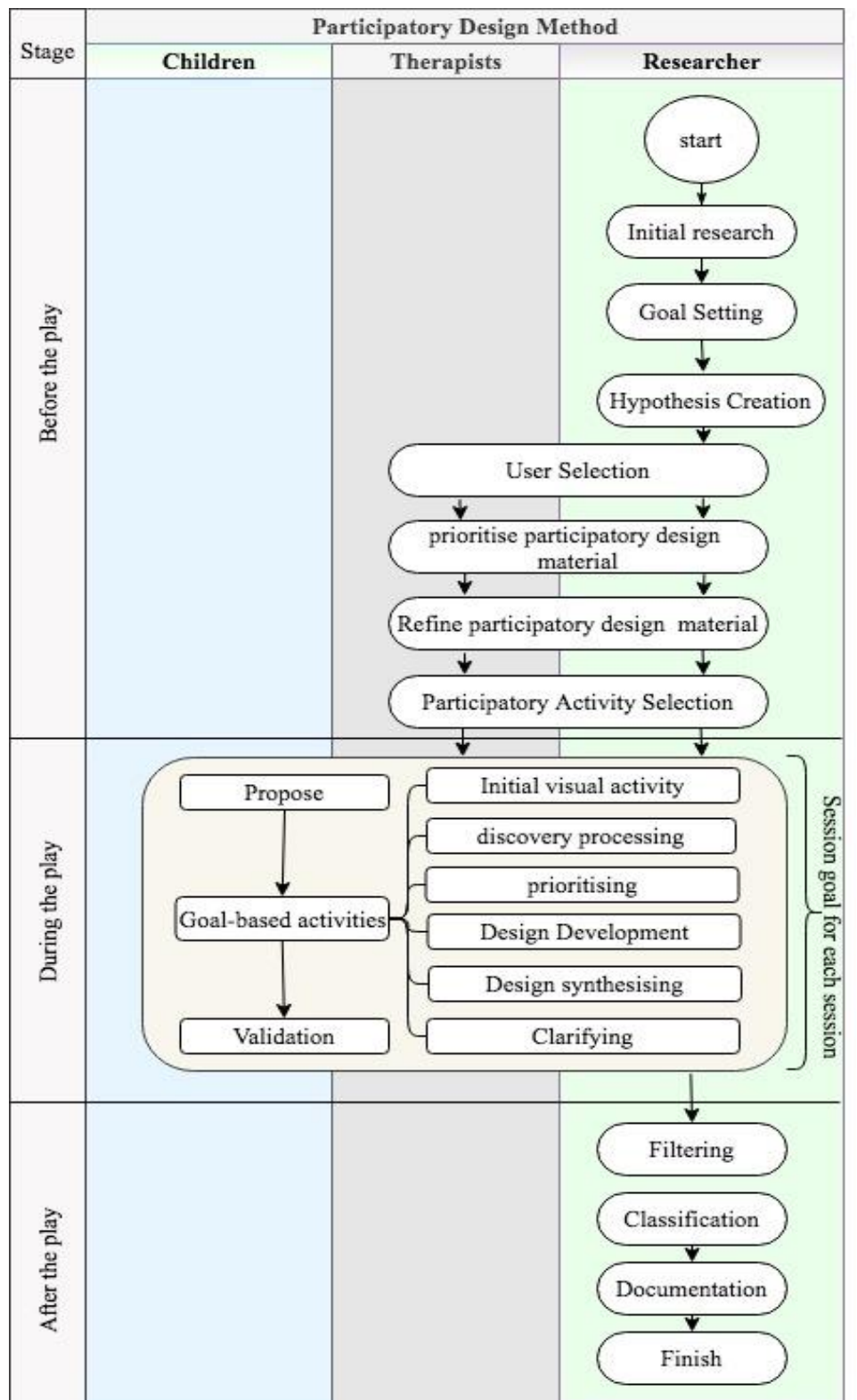

Figure 1. PD workflow with three stages: before the play, during the play, and after the play

\section{Before the Play}

The first stage starts with planning. A minimum form of communication with users was established during the planning phase to discover their preferences through accepted materials. This approach was critical because, when working with children who have ASD, their confidence and motivation will impact the result. Additionally, the main goal of each PD session was identified during the planning phase, and relevant hypotheses were proposed. The following are the critical activities that occur during this stage:

Initial research: Conducting critical initial research is important during this phase to gain a better understanding of the entire project, including participants' preferences and project limitations.

Goal setting: Issues such as the level of involvement of participants, their impairments, the appropriate size of users involved in a group or individual participatory sessions, the appropriate size of design sessions and activities, the quality of available PD methodologies, and the effective role of participants and teachers should be specified and set as sub-goals. 
Hypothesis creation: Initial ideas for various design stimuli were proposed and written on a board, then checked and mapped with the game's primary mechanics and elements to meet the game's goal. Several hypotheses were combined, and others were added. Through the initial research, a better understanding of the main project and its users aided in developing appropriate hypotheses. In general, this study anticipated that children would show less visual interest in social images than in non-social images.

This stage continues with preparing, therapists validated the defined activities and materials to be used in the participatory sessions during this phase. This phase aided in the validation, rejection, combination, or approval of hypotheses. The list of design materials and ideas was generated based on the proposed hypotheses and presented in the form of visual cards to the two therapists for approval during two brainstorming meetings.

Users selection: Children around the age of seven are ideal for co-design sessions because they are responsive to design stimuli and are not yet old enough to have preconceived ideas (Druin et al., 2009). Nonetheless, considering participants as informants makes educational packages more valuable and realistic (Scaife \& Rogers, 1999). Classifying children into groups might prevent the researcher from carefully observing their reactions, resulting in interaction and communication problems during engagement sessions. Besides, children would start to imitate others' behaviours and would be unable to express their reactions independently. On the other hand, managing a single session is much easier, though it takes longer.

Prioritise PD material: Given the age of the users, the researcher should be creative in setting the scene and incorporating scenarios that are familiar to the children (Kelly et al., 2006). In this study, materials included pictures of the context used as prompts or rewards during treatment sessions in a card format. Low-tech materials should be chosen carefully to elicit a high level of contribution from children and to produce a good result.

Therapists were presented with pertinent cards from various categories. Due to the excessive variety of cards, some cards related to musical instruments, stationary (Notepads, eraser, pencil, pen and etc.) and seasonal conditions, outside places such as hospitals, airports, churches, movies and multimedia, holidays, and spare time were removed based on the therapists' experience. The therapists believed that some of the cards were associated with events and locations unfamiliar to the children. Furthermore, most of the cards related to communication verbs and words were not available, as participants were supposed to select their favourite cards. Additionally, their reactions to design stimuli should be assessed rather than their communication skills.

Refine PD material: The last step of material selection was critical because the designed stimuli needed for participants had to be carefully chosen and proposed to be identical based on their knowledge. The combination of non-social stimulus-related Restricted Interest (RI) with the normal stimuli (that are not commonly categorised in the RI area), such as fruits or toys, allowed the researcher to compare and examine the visual exploration potential of both categories. In (Sasson et al., 2008), the list of RI for individuals with ASD was presented as trains, vehicles, planes, blocks, home electronics, computer equipment, road signs, and sporting equipment. Through the use of common non-social stimulus in RI, all participants were able to view the same images. On the other hand, the researcher chose common social images, such as face images (men, women, and children), animals, social events, emotions, body gestures, and characters, which therapists refined. Social stimulus-related faces consisted of clearly happy faces (female and male) and children with direct eye contact. Due 
to a limitation, social stimulus-related social events were excluded because the cards' dimensions were insufficient to present a social event. In addition, the social event cards were limited in quantity. Therefore, the solution was to tap into the children's storytelling ability and allow them to create a story or event with other cards for a social event.

PD activity selection: The activities should be presented in a fun and structured manner to motivate users to participate actively and attentively. They may become frustrated by the unstructured activities. Since the abilities of children with ASD vary, the methodology used with one child may not be appropriate for another. The appropriate solution is always to discuss and adapt plans with caregivers during visits (Millen et al., 2011). The therapists should validate the proposed activities and consider alternative methods if the first session does not engage the children in the design session.

Matchboard: The participant (child) should match each picture at least one time with other relevant items and classify their favourite cards in this activity. The exercise helped the user gain a clear and better understanding of each card. Meanwhile, the therapist removed cards that were not obvious to the participant.

Storytelling: The therapist proposed a series of design cards and used them to tell a short story, which helped improve the participant's imagination and ideal experiences. In this study, the caregiver started a story by presenting relevant cards on the table and making an unfinished story, then asking the participant to fill in the blanks and complete the story. The cards in the blank were usually considered as the participants' favourite cards.

First-then: This 'first-then' activity was helpful to find the cards that usually should be used as a reward or enforcement. In this activity, the therapist provided a photo and proposed, for instance, to play with a car first. A question was then asked, "And then what can we do?." The participant would finish the unfinished task by providing any card, such as having an apple or playing with a doll. The participant's proposed cards were considered favourites.

Sorting cards: To begin, the therapist requested that the participant sort his favourite cards among given options. Following that, the participant was required to sort the cards according to their preference. The therapist was responsible for presenting the cards and initiating discussions about why the cards were grouped; the therapist was no to guide the participant. The participant in this game was required to check all available cards that provided visual support.

The strategy for presenting the design cards is critical for children with ASD. According to the therapist's experience, participants found full-color and object cards, as well as visually high cards, to be too overwhelming. Additionally, presenting all the cards simultaneously may confuse and frustrate them. As a result, it was critical to present the cards incrementally and categorically.

\section{During the Play}

Propose: Each session began with the therapist's greeting. The first 3-5 minutes of each PD session procedure was on initial introduction. The therapist presented some cards to the participant, and the participant was required to recognise some photos. This introduction acquainted the participant with the cards, and they did not need to know all of the cards. This approach increased the participant's comfort level during the PD session. Certain familiar cards prevented the participant from wasting time exploring and checking the proposed cards. 
Goal-based activities: Following the introduction, participants were assigned activities based on the goal of each session. The sessions were divided into the following categories: Session 1: initial visual activity; Session 2: discovery processing; Session 3: prioritising; Session 4: design development; Session 5: design synthesising; Session 6: clarifying.

Validation: The therapist then reviewed the favourite cards and designs from the previous activity after each session. The therapist reused the top five pictures to help the participant recall their previous actions and validate their previous ideas. The therapist then questioned the participant and informed the researcher about the participant's initial knowledge of the photo's subject. Valuing the children's previous work during this phase can help them feel like partners in the design process.

\section{After the Play}

Finally, the data were analyzed, validated by therapists, and incorporated into the designed stimulus. Throughout the PD sessions, all rewarding attempts, verbal and behavioral feedback, reactions, and children's choices were all carefully evaluated. By utilizing visual cards, it was possible to engage the children in basic verbal communication tasks through a structured routine, thereby avoiding frustration and enhancing the concept of understanding and cooperation. The data for this PD study were analyzed qualitatively using observations of six sessions at the Khaneye Mehre Autism School in Iran with 15 participants with ASD aged from 5 to 12 years old. The initial and raw data were gathered through observation notes, post-session reports, visualizations, and verbatim transcripts of the therapists' presentations and discussions with the researcher.

Filtering: After each PD session, the results for each participant were recorded in a table, including all reactions, preference items, and rating scales from the therapists. In some cases, the design stimuli chosen were irrelevant, or the therapist selected the cards and answered his or her questions during the first two sessions. In some cases, the child chose cards based on their proximity to him or her, without regard for their visual design or content. This phase eliminated unreliable, irrelevant, unclear, and incomplete tasks and outcomes from the tables.

Classification: The second phase involved reviewing relevant data and classifying them in tables to ensure the available data were organised. The outcome of this phase was classified as follows: (1) participant quotes, (2) researcher observations, and (3) therapist scales.

Documentation: The last phase was to check the findings and propose the outcome as analysis to demonstrate acceptable social and non-social design stimuli for children.

\section{Findings}

Every child with autism is unique; each participant in this study demonstrated a distinct preference for and response to each style of stimuli within a game, and the range of social and non-social stimulus capabilities varied significantly between participants. Even participants with comparable abilities or impairments would often respond differently to each aspect of a game stimulus. There were some limitations to this study, the first being that the proposed activities were limited to several design cards, with no opportunity for proposing personalised or customised designs. The solution in this situation was to ask for design ideas from participants via drawing, which was not feasible for participants with ASD.

The activities proposed during the PD sessions were structured daily routine activities that therapists supervised. The advantage of this situation is that it may improve participant's motivation to participate in the design process; participants can learn from their behaviors 
and reactions. In PD sessions based on proposed activities, only initial communication was required. For example, the teacher might inquire, "Which one is your favorite?" and the participant showed the chosen card. This strategy was interesting for participants and using minimum of communication skills in sessions engage participants.

\section{Discussion}

During the engagement sessions, the therapists could combine or remove certain activities and materials based on the children's level of interest. The therapist encouraged the participants to think and play independently. There was a break time included in the session in case anyone became bored. During the PD sessions, the therapist should guide the participants towards expressing their ideas rather than what the therapist desires to hear; the rules of the game should be such that there is no correct or wrong answer, and the participants are free to select anything. Additionally, the therapist acted as a neutral third party to facilitate meaningful relation between the participants and the PD result. The therapists should ensure that participants understood the sessions' nature, which was not a treatment but rather a co-design session. This understanding was critical in ensuring the attendance of all participants and maximizing the session's allotted time. The therapists's role was defined as facilitator based on this information.

The cards were created by the researcher and validated by experts. Furthermore, the researcher observed how the therapists and participants interacted and used the cards during the PD sessions. In some cases, the researcher requested that the therapists display specific cards to gauge the participants' reactions. The researcher was to observe the children and their behaviors as an observer. To analyze the data, the researcher had to summarize the sessions' data and add therapist-supplied information about the children's preferences and interests. The final step was to gather and refine the data to create design cues.

The approach taken in this study ensured that participants felt safe and comfortable during the contribution process. Nevertheless, the extent to which they participate should be carefully considered. In this study, defining the participants' roles as co-designers failed due to a lack of communication skills. As a result, the degree to which participants are involved in design sessions should be adjusted. Each session included time for participants to experiment with design elements and create their favorite set using a set of material and narrative-based techniques. Considering the previously mentioned challenges and limitations, the children serve as informants; they are involved in the development of the final product's prototype before its prototype development.

\section{References}

Aguirre, M., Agudelo, N., \& Romm, J. (2017). Design Facilitation as Emerging Practice: Analyzing How Designers Support Multi-stakeholder Co-creation. She Ji, 3(3), 198-209. https://doi.org/10.1016/j.sheji.2017.11.003

Benton, L., \& Johnson, H. (2014). Structured approaches to participatory design for children: Can targeting the needs of children with autism provide benefits for a broader child population? Instructional Science, 42(1), 47-65. https://doi.org/10.1007/s11251-0139297-y

Boyle, B., \& Arnedillo-Sánchez, I. (2016). Exploring the Role of Adults in Participatory Design for Children on the Autism Spectrum. Springer International Publishing Switzerland 2016, 9746(March 2019), 197-208. https://doi.org/10.1007/978-3-319-40409-7

Brandt, E. (2006). Designing exploratory design games: A framework for participation in 
participatory design? Proceedings of the 9th Conference on Participatory Design: Expanding Boundaries in Design, PDC 2006, (May), 57-66.

https://doi.org/10.1145/1147261.1147271

Brunetti, J. M., \& García, R. (2014). User-centered design and evaluation of overview components for semantic data exploration. Aslib Journal of Information Management, 66(5), 519-536. https://doi.org/10.1108/AJIM-12-2013-0153

Chimbo, B. (2016). Cooperative design of a cross-age tutoring system based on a social networking platform. University of south africa.

Constantin, A., Fails, J. A., Good, J., Eriksson, E., Korte, J., Alexandru, C. A., ... Waller, A. (2019). Expecting the unexpected in participatory design. Conference on Human Factors in Computing Systems - Proceedings, (May). https://doi.org/10.1145/3290607.3311758

Drain, A., \& Sanders, E. B. N. (2019). A collaboration system model for planning and evaluating participatory design projects. International Journal of Design, 13(3), 39-52.

Druin, A. (2002). The role of children in the design of new technology. Behaviour and Information Technology (Vol. 21). https://doi.org/10.1080/01449290110108659

Druin, A. (2005). What children can teach us: Developing digital libraries for children with children1. Library Quarterly, 75(1), 20-41. https://doi.org/10.1086/428691

Druin, A. (2015). Cooperative Inquiry: Developing New Technologies for Children with Children. The A-Z of Social Research, 14(99), 592-599. https://doi.org/10.4135/9781412986281.n51

Druin, A., Bederson, B. B., Rose, A., \& Weeks, A. (2009). From New Zealand to Mongolia: CoDesigning and Deploying a Digital Library for the World's Children. Children, Youth and Environments, 19(1), 34-57. https://doi.org/10.7721/chilyoutenvi.19.1.0034

Floyd, C., Mehl, W., Schmidt, G., Wolf, G., Floyd, C., \& Reisin, F. (1989). Out of Scandinavia: Alternative Approaches to Software Design and System Development. HUMANCOMPUTER INTERACTION, 4(1989), 253-350. https://doi.org/10.1207/s15327051hci0404

Frauenberger, C., Good, J., Alcorn, A., \& Pain, H. (2012). Supporting the design contributions of children with autism spectrum conditions. ACM International Conference Proceeding Series, (September 2015), 134-143. https://doi.org/10.1145/2307096.2307112

Gerling, K. M., Linehan, C., Kirman, B., Kalyn, M. R., Evans, A. B., \& Hicks, K. C. (2015). Creating wheelchair-controlled video games: Challenges and opportunities when involving young people with mobility impairments and game design experts. International Journal of Human Computer Studies, 94, 64-73. https://doi.org/10.1016/j.ijhcs.2015.08.009

Golestan, S., Soleiman, P., \& Moradi, H. (2010). A Comprehensive Review of Technologies Used for Screening, Assessment, and Rehabilitation of Autism Spectrum Disorder, (July), $1-12$.

Good, J., \& Robertson, J. (2006). CARSS: A framework for learner-centred design with children. International Journal of Artificial Intelligence in Education, 16(4), 381-413.

Grond, F., Ariel Cascio, M., Motta-Ochoa, R., Tembeck, T., Veen, D. Ten, \& Blain-Moraes, S. (2019). Participatory design of biomusic with users on the autism spectrum. 2019 8th International Conference on Affective Computing and Intelligent Interaction, ACII 2019, 434-440. https://doi.org/10.1109/ACII.2019.8925484

Guzdial, M., Kafai, Y. B., Carroll, J. B., Fischer, G., Schank, R., Soloway, E., \& Shneiderman, B. (1995). Learner-centered system design: $\mathrm{HCl}$ Perspective for the future. Proceedings of the Conference on Designing Interactive Systems: Processes, Practices, Methods, and Techniques, DIS, 23-25-Augu(July 2016), 143-147. 
DEVELOPMENT

Vol. 10, No. 1, 2022, E-ISSN: 2226-6348 @ 2022 HRMARS

https://doi.org/10.1145/225434.225450

Hiniker, A. (2013). Go Go Games: Therapeutic Video Games for Children with Autism Spectrum Disorders. Interaction Design and Children 2013, 463-466.

Hiniker, A., Sobel, K., \& Lee, B. (2017). Co-Designing with Preschoolers Using Fictional Inquiry and Comicboarding, 5767-5772. https://doi.org/10.1145/3025453.3025588

Howes, S. C., Charles, D., Pedlow, K., Wilson, I., Holmes, D., \& McDonough, S. (2019). Usercentred design of an active computer gaming system for strength and balance exercises for older adults. Journal of Enabling Technologies, 13(2), 101-111. https://doi.org/10.1108/JET-12-2018-0057

Joash Sujan Samuel Roy, D. F. (2016). user centered design methods and their application in order to adult community. Lecture Notes in Computer Science (Including Subseries Lecture Notes in Artificial Intelligence and Lecture Notes in Bioinformatics), 9734(July), VII. https://doi.org/10.1007/978-3-319-40349-6

Kelly, S. R., Mazzone, E., Horton, M., \& Read, J. C. (2006). Bluebells: A design method for childcentred product development. ACM International Conference Proceeding Series, 189(January), 361-368. https://doi.org/10.1145/1182475.1182513

Khowaja, K., Salim, S. S., \& Al-Thani, D. (2019). Components to design serious games for children with autism spectrum disorder (ASD) to learn vocabulary. 2018 IEEE 5th International Conference on Engineering Technologies and Applied Sciences, ICETAS 2018, (November). https://doi.org/10.1109/ICETAS.2018.8629208

Kim, M. G., Oosterling, I., Lourens, T., Staal, W., Buitelaar, J., Glennon, J., ... Barakova, E. (2014). Designing robot-assisted pivotal response training in game activity for children with autism. Conference Proceedings - IEEE International Conference on Systems, Man and Cybernetics, 2014-Janua(January), 1101-1106.

https://doi.org/10.1109/SMC.2014.6974061

King, I. C. (2006). "Learner Centered" According to Children. Theory in Practice, 19(February 2015), 133-148. https://doi.org/10.1207/s15430421tip4202

Large, A., Bowler, L., Beheshti, J., \& Nesset, V. (2007). Creating Web Portals with Children as Designers: Bonded Design and the Zone of Proximal Development. McGill Journal of Education, 42(1), 61-82.

Large, A., Nesset, V., Beheshti, J., \& Bowler, L. (2006). "Bonded design": A novel approach to intergenerational information technology design. Library and Information Science Research, 28(1), 64-82. https://doi.org/10.1016/j.lisr.2005.11.014

Madsen, M., Goodwin, M. S., El Kaliouby, R., Picard, R., Eckhardt, M., \& Hoque, M. E. (2009). Lessons from participatory design with adolescents on the autism spectrum. Conference on Human Factors in Computing Systems - Proceedings, 3835-3840. https://doi.org/10.1145/1520340.1520580

Malinverni, L., Mora-Guiard, J., Padillo, V., Mairena, M. A., Hervás, A., \& Pares, N. (2014). Participatory design strategies to enhance the creative contribution of children with special needs. ACM International Conference Proceeding Series, 85-94. https://doi.org/10.1145/2593968.2593981

Malinverni, L., Mora-Guiard, J., \& Pares, N. (2016). Towards methods for evaluating and communicating participatory design: A multimodal approach. International Journal of Human Computer Studies, 94(March), 53-63.

https://doi.org/10.1016/j.ijhcs.2016.03.004

Mazzone, E. (2008). Determining value in informant design with children. Proceedings of the 22nd British $\mathrm{HCl}$ Group Annual Conference on People and Computers: Culture, Creativity, 
Interaction, $B C S \mathrm{HCl} 2008$, 2, 251-252. https://doi.org/10.14236/ewic/hci2008.93

Mazzone, E., Read, J., \& Beale, R. (2008). Understanding children's contributions during informant design. Proceedings of the 22nd British $\mathrm{HCl}$ Group Annual Conference on People and Computers: Culture, Creativity, Interaction, $B C S \mathrm{HCl} 2008,2$, 61-64. https://doi.org/10.14236/ewic/hci2008.34

Miesenberger, K., Edler, C., Dirks, S., Bühler, C., \& Heumader, P. (2020). User centered design and user participation in inclusive R\&D: Introduction to the special thematic session. Lecture Notes in Computer Science (Including Subseries Lecture Notes in Artificial Intelligence and Lecture Notes in Bioinformatics), 12376 LNCS, 3-9. https://doi.org/10.1007/978-3-030-58796-3_1

Millen, L., Cobb, S., \& Patel, H. (2011). Participatory design approach with children with autism. International Journal on Disability and Human Development, 10(4), 289-294. https://doi.org/10.1515/IJDHD.2011.048

Moraveji, N., Li, J., Ding, J., O’Kelley, P., \& Woolf, S. (2007). Comicboarding: Using comics as proxies for participatory design with children. Conference on Human Factors in Computing Systems - Proceedings, 1371-1374.

https://doi.org/10.1145/1240624.1240832

Passerino, L. M., \& Santarosa, L. M. C. (2008). Autism and digital learning environments: Processes of interaction and mediation. Computers \& Education, 51(1), 385-402. https://doi.org/10.1016/j.compedu.2007.05.015

Porcino, T., Trevisan, D., Clua, E., Rodrigues, M., \& Barbosa, D. (2014). A Participatory Approach for Game Design to Support the Learning and Communication of Autistic Children, 8770, 17-31. https://doi.org/10.1007/978-3-662-45212-7

Read, J. C., Sim, G., Gregory, A. J., Xu, D., \& Ode, J. B. (2013). Children Designing Serious Games. EAl Endorsed Transactions on Game-Based Learning, 1(1), e5. https://doi.org/10.4108/trans.gbl.01-06.2013.e5

Sasson, N. J., Turner-Brown, L. M., Holtzclaw, T. N., Lam, K. S. L., \& Bodfish, J. W. (2008). Children with autism demonstrate circumscribed attention during passive viewing of complex social and nonsocial picture arrays. Autism Research, 1(1), 31-42. https://doi.org/10.1002/aur.4

Scaife, M., \& Rogers, Y. (1999). Kids as informants: telling us what we didn't know or confirming what we knew already? The Design of Children's Technology, 1-26. https://doi.org/10.1145/258549.258789

Sik-Lanyi, C., Szucs, V., Shirmohammadi, S., Grudeva, P., Abersek, B., Guzsvinecz, T., \& Van Isacker, K. (2019). How to develop serious games for social and cognitive competence of children with learning difficulties. Acta Polytechnica Hungarica, 16(6), 149-169. https://doi.org/10.12700/APH.16.6.2019.6.10

Soysa, A. I., Al Mahmud, A., \& Kuys, B. (2018). Co-designing tablet computer applications with sri lankan practitioners to support children with ASD. In IDC 2018 - Proceedings of the 2018 ACM Conference on Interaction Design and Children (pp. 413-419). https://doi.org/10.1145/3202185.3202764

Spinuzzi, C. (2004). The methodology of participatory design. Technical Communication, 52(2), 163-174.

Waraich, A., \& Brna, P. (2008). A narrative centred Informant Design approach for interactive learning environments. International Journal of Continuing Engineering Education and Life-Long Learning, 18(2), 181-196. https://doi.org/10.1504/IJCEELL.2008.017375 